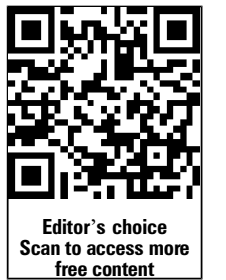

${ }^{1}$ Department of Social Science and Humanities, University of Bradford, Bradford, UK ${ }^{2}$ Faculty of Medicine and Health, Institute of Psychological Sciences, University of Leeds, Leeds, UK

Correspondence to Professor Philip Thomas, Department of Social Science and Humanities, University of Bradford, Bradford, West Yorkshire BD7 1DP, UK; philipfthomas@me.com

Accepted 14 May 2013

Published Online First

8 June 2013

\title{
Madness, childhood adversity and narrative psychiatry: caring and the moral imagination
}

\author{
Philip Thomas, ${ }^{1}$ Eleanor Longden ${ }^{2}$
}

\section{ABSTRACT}

The dominance of technological paradigms within psychiatry creates moral and ethical tensions over how to engage with the interpersonal narratives of those experiencing mental distress. This paper argues that such paradigms are poorly suited for fostering principled responses to human suffering, and proposes an alternative approach that considers a view of relationships based in feminist theories about the nature of caring. Four primary characteristics are presented which distinguish caring from technological paradigms: (1) a concern with the particular nature of contexts, (2) embodied practice, (3) the dialogical basis of caring and (4) the existential basis of caring. From this we explore the role of the moral imagination and our ability, through narrative, to acknowledge, engage with and bear witness to the injustices that shape the lives of those who suffer. This, we argue, is at the heart of caring. Clinical implications are discussed, including an exposition of the importance of narrative in recovery from trauma and distress. Narrative Psychiatry, The Sanctuary Model of care, and Soteria, are outlined as examples of this type of practice.

We live in a time of austerity, an economic recession that has major implications for our communal health and well-being. Whereas past debates in Britain about the relationship between health and socioeconomic factors focussed on social class and absolute poverty, ${ }^{1}$ recent work highlights the importance of relative poverty. ${ }^{2}$ In this analysis, childhood adversity emerges as an important mediating factor between material disadvantage and poor adult mental health. However, scientific theories that downplay the role of contexts dominate psychiatric theory and practice. ${ }^{3}$ In this paper, we examine the implications of scientific and technological modes of thought for psychiatric theory and practice. How does scientific knowledge stand in relation to lives afflicted by adversity, abuse and oppression, and live in horror and fear? What are the moral implications of applying this knowledge to states of madness ${ }^{\text {i }}$ ? Are there philosophical and conceptual ways of engaging with the moral dilemmas posed by the use of technological interventions, such as pharmacotherapy and cognitive

'We use 'mad' and 'madness' to avoid the aetiological assumptions that permeate words like psychosis or schizophrenia. Additionally, these terms carry other meanings that resonate powerfully with a sense of moral outrage. We will see that this becomes more prominent at the end of this paper. For similar reasons we use the word 'distress' in place of 'depressive disorders' or 'anxiety disorders'. therapy (CT), in the lives of people for whom childhood adversity becomes a soul-destroying narrative strand in adulthood? Is there a role for the imagination in caring? Finally, are there ways of working with people who experience madness that engage with the moral and ethical complexities of the relationship between knowledge/power and suffering?

We begin by outlining the technological paradigm of mental health practice. There is growing concern within clinical psychology and psychiatry ${ }^{4-8}$ about the inability of this paradigm to engage with the narratives and contexts of people who experience madness. Most significant are the voices of people who use mental health services. While it is true that some value the diagnoses and treatments engendered by the technological paradigm, many do not; instead, regarding such frameworks as stigmatising, disempowering and obscuring the impact of lived experience. $^{9-11}$ Thus, a tension exists between understanding madness through its sociocultural and interpersonal contexts, and current scientific accounts of madness and the technological interventions derived from this. We examine this tension through a version of the technological paradigm, which in recent years has provided a scientific account of associations between trauma, social adversity and psychosis. The critical issue is whether this is better suited to promoting moral and ethical interactions than dominant biomedical models. We argue that in psychiatry, the technological paradigm is limited in its ability to foster truly principled responses to suffering. We develop this argument through a view of human relationships based in feminist theories about caring. This draws attention to the importance of what we call the moral imagination which, in our view, is at the heart of caring. It also raises the importance of narrative in clinical practice.

\section{THE TECHNOLOGICAL PARADIGM AND PSYCHOSIS}

In one guise or another, the biomedical model has dominated psychiatric theory and practice for 150 years. ${ }^{12}$ Although its prominence has varied from time to time, the publication of the Third Edition of the Diagnostic and Statistical Manual (DSM-3) heralded the dawn of a new biological psychiatry in the USA, ${ }^{13}$ and across the globe. ${ }^{14} 15$ In contemporary psychiatry, the biomedical model is part of the technological paradigm. ${ }^{16}$ We use this expression because in addition to pharmacotherapy, psychiatric interventions increasingly include CT based in theories of inner representational processes rather than medical frameworks. Pharmacotherapy and CT share the following assumptions ${ }^{8}$ : 
- Mental health problems arise from disordered mechanisms. These involve abnormal physiological/psychological events that occur within the individual.

- These mechanisms can be modelled in universal causal terms. They can be accounted for independently of the particular contexts in which they occur.

- Interventions based in the technological paradigm are instrumental, and can be designed, evaluated and implemented independently of human relationships, values and narratives.

This paradigm explains distress and madness using the same causal logic found in other branches of medicine. Technical interventions in psychiatry are conceptualised as specific therapeutic acts targeted at specific syndromes or symptoms. However, the success of this paradigm in general medicine (eg, improving health outcomes by enhancing treatment safety and efficacy) is not replicated in psychiatry. Empirical evidence from within the technological paradigm simply does not support the assumptions on which it is based. The paradigm is currently in crisis. In the USA, Angell's recent review ${ }^{17}$ describes how the interests of the pharmaceutical industry have obliterated confidence in scientific claims for the effectiveness of psychotropic medication. In Britain, recent evidence has undermined clinical and scientific conviction in the so-called second-generation neuroleptic drugs, whose ascendancy has been described as '...a tale of profit over patient benefit, of marketing over ethics... of fabricated classes, money and marketing' (ref. 18, p. 266-7).

Recent evidence indicates that non-specific factors like hope, the expectation of improvement and the placebo effect are at least as, if not more, effective than specific properties of pharmacotherapy and $\mathrm{CT}^{8}$ The reasons for this are complex. In medicine, the technological paradigm deals primarily with physical malfunctions that are generally supported by explicit empirical evidence ${ }^{\text {ii }}$. In other words, their construct validity is well established. This is not the case for functional psychiatric diagnoses. Additionally, regarding madness as (unsubstantiated) dysfunction may potentially silence the person's narrative. ${ }^{19}$ This can occur in a variety of ways, from earlier forms of biological reductionism famously and eloquently attacked by Laing, ${ }^{20}$ to descriptive psychopathology which, by focussing on the form of experience rather than the content, decontextualises the experiences of madness. ${ }^{3}$

However, recent developments in scientific knowledge have drawn attention to the importance of adversity and abuse in madness. The traumagenic neurodevelopmental (TN) model ${ }^{21}$ proposes that the impact of trauma on the developing brain ${ }^{\text {iii }}$ causes psychosis. By contrast, biomedical models minimise the role of trauma and social adversity to mere triggers that disclose an underlying biological vulnerability. The TN model challenges this, claiming that vulnerability to psychosis is not genetically inherited, but acquired as a result of a reciprocal interaction between environmental distress and psychological and biological

\footnotetext{
iisome may see this as an unjustifiably broad statement. There is unequivocal empirical evidence of a physical basis for many serious diseases (eg, cancer, diabetes, neurological disorders), and this evidence provides a rational basis for specific interventions. The somatic basis for many chronic physical conditions (eg, asthma, arthritis, chronic pain) may be less clear, but nevertheless, there are empirically identifiable physical factors that make an important contribution to aetiology, and which are amenable to physical interventions.

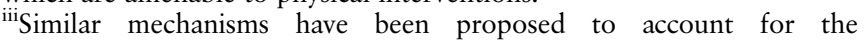
relationship between the raised incidence of psychoses in African-Caribbean people in the UK and the daily context of racism and racial abuse that black people experience in British society. ${ }^{22}$
}

elements $^{\text {iv }}$. This model is interesting because although it is a variant of the technological paradigm, it differs from it in a crucial respect. It proposes that madness arises from disordered mechanisms or processes in the individual (assumption 1), and it models these processes in causal terms (assumption 2), but it differs critically from the biomedical paradigm because it foregrounds the importance of personal contexts of abuse and adversity in which these processes originate.

The TN paradigm highlights the value of scientific inquiry unsullied by commercial interests in challenging what Thomas Kuhn called 'normal science'. ${ }^{30}$ Additionally, there will be real value in the improved technological interventions that it will give rise to, but simultaneously, it places moral issues of power and abuse in human relationships and our social organisation centre-stage in understanding madness. This raises important questions about the moral basis of our engagement with suffering, as scientists, clinicians and practitioners. If we accept the primacy of early life experience in the origins of madness, and its link with social adversity, what are the implications of this insight for how ought we to help those who suffer?

Kleinman ${ }^{31}$ addresses this question in terms of an imbalance between empiricism in medicine, and medicine as art: 'The balance between science/technology and art had shifted so far towards the former that the latter is a pale shadow, a fragile remnant of what had for centuries been crucial to the work of the doctor' (ref. 31, p. 22). 'Caring', he argues, is a foundational component of moral experience, '....an existential quality of what it is to be a human being' (ibid: p. 23). At this point, we will examine in detail what we mean by caring.

\section{CARING AND THE MORAL IMAGINATION}

Feminist thinkers like Carol Gilligan and Nel Noddings have emphasised the way that logic, reason and an emphasis on abstract general principles have dominated moral discourse ${ }^{\mathrm{v}}$. Through empirical studies of women discussing moral problems, such as abortion or contraception, Gilligan ${ }^{34}$ describes an 'injunction to care' as a moral imperative, manifest as a responsibility to

${ }^{\text {iv }}$ This view, although obscured by later emphases on biogenetics, was articulated in the original conception of the stress-vulnerability model. ${ }^{23}$ The TN model's emphasis on trauma is also consistent with other explanatory frameworks, including dissociation. Although dissociative processes may initially function as protective survival strategies to endure intolerable pain, fear and stress, ${ }^{24}$ their long-term impact appears less benign, and dissociation has been implicated as a significant mediator between childhood trauma and subsequent psychopathology. The clinical and conceptual overlaps between dissociation and psychosis have been noted by numerous authors, ${ }^{25-28}$ and in turn, the prominence of traumatic events is supported by a recent meta-analysis of patient-control, prospective and cross-sectional cohort studies (many of which, among other variables, controlled for genetic liability), which demonstrate beyond reasonable doubt how childhood adversity significantly increases the risk of psychotic breakdown. ${ }^{29}$

"See also the work of Sevenhuijsen ${ }^{32} 33$ for consonant feminist considerations and perspectives on morality, justice, and the ethics of care. We acknowledge that some, like Hassan (see http://dspace. sunyconnect.suny.edu/bitstream/handle/1951/43954/

An_Ethic_of_Care_Critique.pdf?sequence $=1$ ) have criticised Nodding's work on the grounds that it may be seen to support traditional gender roles for women, a position that runs counter to the objectives of feminism. However, our purpose in using Nodding's work is not to support gender roles, but to develop a set of arguments that justify a principled and moral engagement with madness. We agree, however, with the implications of Hassan's account of 'engrossment' in the Other, and the displacement of one's own values with those of another person. However, our view is that whilst this criticism is appropriate in the context of the relationship between husband and wife, it is less of a problem in healthcare settings. 
bear witness to, and attempt to alleviate the 'real and recognisable trouble' of the world (ref. 34, p. 100). Women preferentially consider moral dilemmas through the particular, by placing themselves in the position of the participants. This moves the discussion away from abstract general principles based in rule-governed hierarchies, or what Noddings calls the 'language of the father' (ref. 35 , p. 1), to an embodied involvement in the participants' dilemmas, experienced through the feelings that particular circumstances invoke. The difficulty, as Gilligan points out, is that ratiocinative views dominate moral discourse.

Noddings ${ }^{35}$ also notes that women are more likely to ask questions that draw out the complexities and ambiguities of human relationships. They want to know what it is like to be the participants in a particular moral dilemma, and are less likely to focus on general principles. She argues that this approach is more natural and realistic, because a concern with moral decisions should be situated in the particular context of people's lives. This requires an approach that is qualitatively different from rational analysis. This is important for our argument. The technological paradigm is based in abstract general principles that possess their own internal logic and rules, ${ }^{16}$ but these are used in clinical settings that are simultaneously located within embodied human relationships and contexts. There are four aspects of caring arising from feminist theory that can help to clarify the moral basis for a psychiatric practice based in scientific knowledge. These are (1) a concern with the particular nature of contexts, (2) embodied practice, (3) the existential basis of caring and (4) the dialogical basis of caring.

\section{Concern with the particular nature of contexts}

Gilligan argues that the 'masculine approach' that characterises the scientific gaze involves the use of abstraction, which estranges moral action from the narrative aspects of the participants' lives. This may help in grappling with general moral principles, like justice, but it detaches moral problems from their existential contexts. If, on the other hand, we engage with the uniqueness of the individual life, it becomes '...possible to consider the social injustice that their moral problems may reflect and to imagine the individual suffering their occurrence may signify or their resolution engender' (ref. 34, p. 100). We interpret this to mean that in mental health practice, caring must involve engagement with particular contexts of the individual's life, especially the circumstances within it, that are important if we are to understand the meaning of their suffering.

\section{Embodied practice}

Embodiment reflects a primary concern with physical sensation and emotional feeling, in contrast with the rational, disembodied (feeling-less, emotion-less), objective stance that characterises a scientific view of the world. The concept of embodiment is rich and multilayered. Here, we use it in the sense given by Merleau-Ponty, ${ }^{36}$ who argues that the subject of experience is not a disembodied Cartesian ego, but a bodysubject. In our day-to-day presence in the world we do not experience ourselves as pure consciousness detached from the world and our bodies. Our preobjective experience ${ }^{\mathrm{vi}}$ is only possible by virtue of our possession of bodily senses. We can, of course, examine the world, our bodies and the bodies of others scientifically-as objects in the world to be accounted for

\footnotetext{
${ }^{\mathrm{vi}}$ This is the expression Merleau-Ponty uses to refer to our immediate experience of the world as it is already present to us, potentially meaningful, and before we analyse it scientifically or break it down into causally related elements.
}

through causal processes and general laws-but in terms of our being-in-the-world that is not how we experience the body. We can no more separate other human beings from their embodiment than we can separate ourselves from our own bodies. As Eric Matthews writes: 'In this way, the world as we perceive it is again a world of meanings, which include our own bodies and other embodied persons as having particular sorts of meaning for us.' (ref. 37, p. 60, emphasis in original).

Noddings argues that feelings and emotions are central to our ability to care for others. It is through my sense of myself as an embodied being, existing in a particular relationship or situation at a particular moment in history and culture, that it is possible for me to see someone else's reality as a possibility for my own. It is this that underlies our ability to feel compassion for another (in the sense of participating in, and engaging with, another's suffering) that we will see is a vital element of caring. Thus, the experience of the suspicious and paranoid client ceases to be a 'discourse of deficit ${ }^{38}$; instead we empathise with her enduring, embodied fear, and how she has learnt it in order to help her negotiate and regulate the social world. We do not ask what's wrong with her; rather, what's happened to her. ${ }^{39}$

\section{Existential basis of caring}

The embodied nature of caring suggests that it is a fundamental existential feature of human life. Kleinman ${ }^{31} 40$ makes precisely this point. Existential perspectives deal primarily with our relationship with the world we encounter before us. The expression used by Heidegger ${ }^{41}$ to describe this, 'being-in-the-world,' captures the inseparable nature of this relationship ${ }^{\text {vii }}$. There is a strong element of choice in how we engage with those whom we encounter in our social worlds, and for existentialism this raises questions about our moral engagement with others and the world. Nodding's stance on caring is partly drawn from existential philosophy, especially Martin Buber's notion of 'I-Thou.' Buber $^{43}$ distinguishes between our relationship to the world of objects ('I-It') and the existential basis of our relationship to other beings ('I-Thou'). This draws attention to the dialogical basis not only of existence (being-world), but of our relationship to others (I-Thou). Technological modes of thought involve measurement, analysis and abstraction of the other, placing us in an 'I-It' relationship. This means that caring involves much more than perceiving individuals as technical problems that require fixing and modifying through medication or therapy.

Noddings sees the existential basis of caring as a heightened sense of awareness of the world, of the other and of the self. This is fostered through a receptive mode of being that is both reflective and reflexive. That is to say, as well as leaving myself open to reflect upon the other, I open up to myself so as to become aware of myself in relation to the other (reflexive). In this mode I may become aware not only of what I have received from the other, but I may also have to decide whether to respond to it or not. If I choose the latter course this denial may induce guilt ${ }^{\text {viii }}$. Guilt plays an important role in caring,

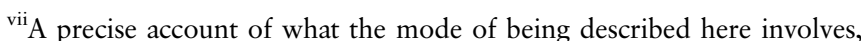
or how it is experienced, is beyond the scope of this paper. In part, this is because it concerns the way we directly experience the world before we come to describe it in words. For a more detailed discussion of this, including a relevant thought experiment, see ref. 42

viii The importance attached to the emotional basis of caring takes us back to the earlier point about embodiment. By contrast, the technological paradigm, whose objectivity can only been maintained at the expense of detachment from personal feelings, embodied caring is only possible if we engage with our emotional responses to the other.
} 
functioning both as a signpost and a turning point. Experiencing guilt may lead me to adopt the rational-objective mode of thought as a way of assuaging it, and in this mode I become detached from the cared-for. On the other hand, guilt may impel me to consider possible courses of action available to me if I do decide to respond to the other. This reflective imperative is at the core of moral imagination: a dialogical view of self that encompasses the person who experiences psychosis, and the person working with him or her (a self, ie, not engrossed or completely given up to the Other, as Hassan implies: see footnote v). In our view of caring, there is dialectical juxtaposition of subjectivities, a reciprocity.

\section{Dialogical nature of caring and the moral imagination}

It follows from the foregoing that caring is fundamentally relational, based in an engagement between two human beings. Noddings uses the terms 'one-caring' for the person who is in the position of administering care, and 'cared-for' to denote the recipient. For the one-caring, this means maintaining a particular disposition, or bestowing oneself (in the sense of conferring a gift) and making oneself available ${ }^{\mathrm{ix}}$. This is how the one-caring is present to the cared-for. These expressions highlight the fundamentally relational nature of caring, based in the dialogical nature of subjectivity. Furthermore, this emphasis on compassion, relatedness and connection is empowering for friends, family and community through negating the idea that only trained 'experts' can administer meaningful support to the mentally distressed ${ }^{\mathrm{x}}$.

We use the word dialogical here in the sense developed by the Russian literary critic Bakhtin, ${ }^{46}$ whose ideas have implications for our awareness of difference and our relationship to it. Language and consciousness originate in two people in dialogue with one another, in a particular place and time. Bakhtin asks how do they organise themselves into an 'I' and an 'Other', and what role does language play in this? He maintains that language deals fundamentally with the issue of alterity. There is no such thing as a neutral language spoken in a detached impartial voice devoid of context. Human beings are embodied beings set within a social world; we speak from a particular position in space and time in which our perceptions are subject to constant judgements originating in our unique positions in culture and history. Thus, the dialogical basis of subjectivity grounds our understanding of a moral life. Additionally, it places moral questions in the space between two or more people, and this moves us away from thinking about ourselves as moral subjects in terms of universal principles. Human predicaments are unique, and must be considered as such ${ }^{\mathrm{xi}}$. This, as we will argue shortly,

\footnotetext{
${ }^{\mathrm{ix}}$ In later work, Noddings ${ }^{44}$ also draws attention to a more general aspect of caring, caring-about, that is necessary for a sense of social justice and fairness, and which contributes to social capital. This is clearly important for the relationship between socioeconomic inequality and childhood adversity although there is no space to explore this here. ${ }^{\mathrm{x}} \mathrm{A}$ recent multiauthor text ${ }^{45}$ provides a rich demonstration of the importance of informal and organised systems of self-help and community support for people who experience madness, as well examples of the different ways that professional support can work alongside and complement these systems.

${ }^{x}$ Perhaps the most complete and insightful Bakhtinian exposition of psychiatric care is to be found in Peter Good's Language for Those Who Have Nothing ${ }^{47}$ which opens out the moral complexities that surround the psychiatry's power to account for the experiences of those identified as mad (based in his experiences as a participant observer and 'pseudopatient' in a psychiatric unit.
}

draws attention to the important role of narrative in clinical practice.

The sense of compassion, of participating in, and engaging with another's suffering, is an important aspect of what we call the moral imagination. But there is more to it, particularly where madness is involved. It involves our ability to place ourselves in a particular disposition or frame of mind, towards the Other. This disposition has much in common with the way we relate to characters in a novel (see also footnote vi). We are curious about them, open and receptive to their feelings and thoughts, ever prepared to be surprised by them. As we read we reflect on how we might feel and respond were we in similar situations as the protagonists. This act of self-reflection is central to the role of the moral imagination in caring, especially in narrative psychiatry. It also draws attention to the importance of literature and an immersion in the literary for the practice of medicine and psychiatry. ${ }^{48} 49$

The moral imagination is a central feature of the dialogical basis of subjectivity, and in our view lies at the heart of narrative psychiatry. This is because it involves our ability to distinguish different alternatives for acting in a particular circumstance, to envisage the latent consequences, penalties, or benefits that may result from one's conduct ${ }^{50}$; and in doing so sustain an imaginative curiosity that tolerates complexity and ambiguity, while at the same time rejecting polarity. ${ }^{51}$ As such, we have argued for the need to place this type of ethical decision making at the centre of mental health practice.

\section{CARING, NARRATIVE AND RECOVERY}

These four features delineate the moral and existential basis of the trust necessary for therapeutic relationships in mental health practice. Our contention is that they provide the holding matrix that contains all other interventions, including those of the technological paradigm. By prioritising the theory and practice of caring, we believe it is possible to place scientific knowledge, and the technological interventions derived from it, in a more appropriate relationship to suffering ${ }^{\text {xii }}$. For Gilligan and Noddings, narrative establishes the moral basis of human relationships, and our involvement as psychiatrists and psychologists in narrative is essential in placing the suffering person at the centre of the moral universe in our work. This is vital for recovery. Just as the self can be undone and dehumanised by brutality and isolation, it can be renewed and remade through solidarity and connection with others through narrative. Indeed, this perspective is congruent with the broader tenets of medical humanities, wherein narrative medicine is believed to fortify clinicians with the proficiencies to identify, decipher and empathise with testimonies of suffering, and honouring patients' stories is

\footnotetext{
${ }^{x i i}$ Our position is not one that opposes the use of scientific methods in mental health practice. Our position in relation to the role of science and technology in human affairs is close to that of Matthew's ${ }^{37}$ reading of Merleau-Ponty. Some have argued that Merleau-Ponty was antiscience, a view contested by Matthews, who points out that in the original translation of Phenomenology of Perception, the French word désaveu was incorrectly rendered as a 'rejection' (of science), when a better word is foreswearing as it appears in the later translations. ${ }^{36}$ This indicates that Merleau-Ponty was not hostile to science, but wanted to place it in a more appropriate relationship to human experience. We follow Matthews here. The question of the position of science in relation to madness is one of priorities. Our argument, following Merleau-Ponty and Matthews, is that caring comes before science and that scientific and technological interventions should, before all else, be based in the notion of caring outlined in this paper.
} 
claimed to facilitate more compassionate, effective and ethical care. $^{49} 52$

In her book, Aftermath: Violence and the Remaking of the Self, philosopher Susan Brison ${ }^{53}$ interweaves her account of a murderous sexual assault in which she was left for dead, with her philosophical reflections on these shattering events. She writes extensively about the importance of narrative in her recovery: 'The communicative act of bearing witness to traumatic events not only transforms traumatic memories into narratives that can...be integrated into the survivor's sense of self and view of the world, but it also reintegrates the survivor into a community, re-establishing bonds of trust and faith in others.' (ref. 53, p. xi).

Brison deals with two aspects of narrative that are pertinent to recovery in madness, and which are implicit in our argument: narrative's reconstructive function, and its role in the moral struggle for justice through social networks, what Herman characterises as 'the restorative power of truth-telling' (ref. 24, p. 181) and Dillon as 'an internal process of truth and reconciliation' (ref. 54, p. 145). Brison points out that most of us share the belief that we ought to live in a fair world where nothing unjust will happen to us. The link between early adversity and madness ${ }^{\text {xiii }}$ indicates that this is not so. Nevertheless, in the face of both calculated abuse and arbitrary tragedy, we struggle against the current as we try to maintain this belief. This may encompass outrage and incomprehension: not just ' $w$ hy' but 'why me?" 24 The world is unjust, and this is why acknowledging injustice is vital for recovery. Working with people whose distress originates in early adversity thus necessitates moral solidarity that bears witness to suffering (ref. 3, especially pp. 21536). Although narrative plays a central role in the reconstruction of self necessary for recovery, the limitations of language can impose restrictions on our ability to speak of trauma. Suffering can be ineffable, and unconstructed trauma stories are necessarily circumscribed, petrified and 'pre-narrative'. 55 xiv There is also an overlap to be explored here with Frank's ${ }^{58}$ typology of illness narratives, particularly chaos and quest narratives. Our ability to attach words to our experiences enables us to communicate these to others. This is why many people find non-linear forms of narrative like poetry, and non-textual forms of expression, such as dance and painting, helpful in early recovery.

Brison also explores how social networks and collective moral action guided her healing. One drawback of therapy for abuse survivors is that it fails to address injustice, and the wider political and cultural contexts in which injustice arises. This is why organisations like the Hearing Voices Network (HVN), and other collectives constituting the wider survivor movement are so important in the field of mental health, wherein the personal is also the political. ${ }^{54}$ Such networks foster solidarity, validation, and may ultimately help individuals take control of narrative processes for themselves. ${ }^{\mathrm{xv}}$ This means that in addition to

\footnotetext{
xiii Although Brison is writing about recovery from adulthood trauma, her emphasis on the role of narrative in recovery is relevant to the suffering of people whose traumatic experiences occurred much earlier in life.

${ }^{\text {xiv }}$ Kofman ${ }^{56}$ conveys this vividly in her account of her father's death in Auschwitz. Most forms of narrative prioritise certainty, coherence, intelligibility, and linearity (ie, temporal order). The problem, as Stone ${ }^{57}$ argues, is that this suppresses otherness. To use Bakhtin's expression, they are monological. Kofman uses the expression writing without power (écrire sans pouvoir) to refer to narrative and discursive modes that open up the possibility of speaking about trauma that engage with the other.
}

caring, professionals must stand alongside those who have experienced oppression and abuse. We too must bear witness to suffering. As described by Wilson and Droždek, 'We live in a world where broken human spirits abound and surround us with their silent cries and unspoken loneliness' (ref. 59, p. 109). Whereas trauma is defined by shame, seclusion and helplessness, healing thus takes place in a crucible of empowerment, validation and fellowship. ${ }^{24} 5354$ Trust and caring are prerequisites here. These new perspectives do not change the narrative, but from retelling and reflection back from others, new meanings emerge, and the story thus transforms into testimony as part of the ritual of healing. ${ }^{60}$

\section{IMPLICATIONS FOR CLINICAL PRACTICE}

This analysis raises important questions for psychiatry and psychology, the most pressing of which concern the basis of clinical practice. How ought we to work with people whose experiences originate in the most extreme forms of human suffering and adversity? There are two conclusions we will outline in answer to this question. The first concerns two forms of practice that already prioritise caring as we have described, the Sanctuary Model, and Soteria. The second is the value of narrative psychiatry as way forward for psychiatric practice.

The Sanctuary Model, ${ }^{39}$ was conceived to 'facilitate the development of structures, processes, and behaviours on the part of staff, clients and the community-as-a-whole that can counteract the biological, affective, cognitive, social, and existential wounds suffered by the victims of...extended exposure to adversity' (ref. 61, p. 357). The model's theoretical basis derives from systems theory, trauma research and the principles of therapeutic communities, which are drawn together in the Seven Sanctuary Commitments: non-violence, growth and change, open communication, emotional intelligence, inquiry and social learning, shared governance and social responsibility. An important element of the Sanctuary Model is its focus on individual and organisational needs to develop safe and healing environments where the 'one-caring' and 'cared-for' can thrive. Thus, the Sanctuary Tool Kit (eg, safety and treatment planning, self-care, psychoeducation) is a set of simple, practicable interventions that augment the model's philosophy and are applied for the mutual benefit of both staff and service users. ${ }^{39}$

Soteria (the Greek for deliverance or salvation) was the name given by psychiatrist Loren Mosher to a crisis house set up to help people through acute psychoses with minimal medication. ${ }^{62}$ Mosher, influenced by Laing and existentialism, conceptualised psychosis as an altered state of consciousness in response to severe crisis or trauma. ${ }^{63}$ Staff are encouraged to engage with residents' feelings, beliefs and experiences, and to see in them the potential for psychological growth and reconstitution. This is guided by the view that psychosis is simply an extreme expression of fundamentally human experiences. Soteria relies on 'being with', 42 an existential engagement between staff and acutely psychotic residents, that shares much in common with caring as set out above. Workers are open to the world as the resident finds it, and accept the reality of the other person's experiences, without having to intervene, or make normative judgements. A recent systematic review of

\footnotetext{
${ }^{\mathrm{xv}}$ Our experience of the HVN is that groups are truly polysemic in that their members rely on a wide range of narratives in talking about, and making sense of their experiences. These include the spiritual, the conspiratorial, the political, the traumatic, the psychological and the medical.
} 
Soteria has shown that it is as effective as conventional drug treatment for people experiencing acute psychosis, with marginally better social outcomes. ${ }^{64}$

The second development is set out in Bradley Lewis's recent book, Narrative Psychiatry. ${ }^{65} \mathrm{He}$ proposes that one way of looking at the limitations of scientific and technological psychiatry is its sterility: it simply says nothing about the complexity of human lives and their dilemmas. He uses Chekhov's play, Ivanov, to illuminate what he means by a narrative view of psychiatric practice. This is a view that engages with the multiplicity of meanings, and thus, the indeterminacy of human lives. There is no single, monological truth about human beings, but this does not mean a descent into the morass of relativism. Instead, he argues that it forces us to engage with our patients' (and our own) values, and ultimately the moral implications of psychiatric practice. This is because narrative psychiatry is not concerned with the truth status of different stories, but with the consequences of different stories about madness and distress, and the sort of lives that arise from these stories. The arguments we have put forward here about the dialogical and existential basis of caring support this view. Lewis sees psychiatric practice in terms of prioritising clinical stories. Patients enter the clinic with a vast array of complex narratives; the most important task for the psychiatrist is to engage with these stories respectfully and empathically. This means caring for and about the person whose story you are listening to. His use of Chitra Divakaruni's short story Mrs Dutta Writes a Letter in the final chapters of his book sets out how narrative psychiatry works in practice, while at the same time drawing attention to the importance of literary narratives in understanding clinical practice.

\section{CONCLUSIONS}

In general medicine, Mol (ref. 66, p. vii) argues that '[a]ttending to enactment rather than knowledge has an important effect: what we think of as a single object may appear to be more than one,' wherein medicine's ontological politics influence 'the way in which problems are framed, bodies are shaped and lives are pushed and pulled into one shape or another' (ibid, p. viii). Correspondingly, we suggest that a focus on trauma, testimony and polysemy raise important considerations for how mental health narratives are situated within medical humanities research. We suggest that without a framework more clearly derived from the tenets outlined above, technological approaches at best risk complicity in abuse and injustice, and at worst actively perpetrate it. Maltreatment, disempowerment and hierarchal inequalities thus become enacted within the personal, the professional and the political, with the client growing progressively estranged and disenfranchised from their society, their community and the value of their own narrative. ${ }^{54}$ By contrast, we suggest that promoting moral emphases on healing, truthtelling, emotional resonance and political and interpersonal dignity is ethical in purpose and transformational in scope. As Dillon observes: '[W]e have a collective responsibility to people who have experienced abuse to acknowledge the reality and impact... and support them to get the help they need... We must expose the truth and not perpetuate injustice further. Otherwise today's child abuse victims will become tomorrow's psychiatric patients' (ref. 67, p. 18).

Much more work remains to be done in exploring the role of the moral imagination in caring in madness. The next stage of this work will set out its relationship to literary theory and hermeneutics, as well as explore the role of literature and creative writing in helping psychiatrists to engage with their patients' stories. There is also much to be gained from exploring the moral value of narrative in psychiatric practice from the perspective of Frank's work ${ }^{58}$ on illness narratives. Foregrounding the existential basis of caring and outlining the role of the moral imagination is, in our view, fundamental to the practice of narrative psychiatry.

Acknowledgements We are grateful to Dr Pat Bracken and Dr Brendan Stone for comments on an earlier draft of this manuscript.

Contributors PT and EL drafted the first version, which was then written by PT, then edited by EL and finally agreed by both authors before first submission. The revised manuscript was edited and written by EL, then by PT, and the final, submitted version agreed by both authors.

Competing interests None.

Provenance and peer review Not commissioned; externally peer reviewed.

\section{REFERENCES}

1 Black D, Morris JN, Smith C, et al. Inequalities in health: the black report. Harmondsworth, England: Penguin, 1982.

2 Wilkinson R, Pickett K. The spirit level: why equality is better for everyone. London: Penguin, 2009.

3 Bracken P, Thomas P. Postpsychiatry: mental health in a postmodern world. Oxford, England: Oxford University Press, 2005.

4 British Psychological Society Division of Clinical Psychology. Good practice guidelines on the use of psychological formulation. Leicester, England: British Psychological Society Division of Clinical Psychology, 2011.

5 Read J, Bentall RP. Negative childhood experiences and mental health: theoretical, clinical and primary prevention implications. Br J Psych 2012;200:89-91.

6 Boyle M. Making the world go away, and how psychiatry and psychology benefit. In: Rapley M, Moncrieff J, Dillon J.eds. De-medicalizing misery: psychiatry, psychology and the human condition. Eastbourne, England: Palgrave Macmillan, 2011:27-44.

7 Kleinman A. Rebalancing academic psychiatry: why it needs to happen-and soon. Br J Psych 2012;201:421-2.

8 Bracken $\mathrm{P}$, Thomas $\mathrm{P}$, Timimi $\mathrm{S}$, et al. Psychiatry beyond the current paradigm. $\mathrm{Br} \mathrm{J}$ Psych 2012;201:430-34.

9 Mental Health Foundation. Knowing our own minds: a survey of how people in emotional distress take control of their lives. London: Mental Health Foundation, 1997.

10 Faulkner A, Layzell S. Strategies for living: a report of user-led research into people's strategies for living with mental distress. London: Mental Health Foundation, 2000.

11 Geekie J, Read J. Making sense of madness: contesting the meaning of schizophrenia. Hove, England: Routledge, 2009

12 Marx 0. Nineteenth-century medical psychology: theoretical problems in the work of Griesinger, Meynert, and Wernicke. Isis 1970;61:355-70.

13 Wilson M. DSM-III and the transformation of American psychiatry: a history. Am J Psych 1993;150:399-410.

14 Bass JK, Bornemann TH, Burkey M, et al. A United Nations General Assembly special session for mental, neurological, and substance use disorders: the time has come. PLoS Med 2012;9:e1001159.

15 Collins $P$, Patel V, Joestl $S$, et al. Grand challenges in global mental health. Nature 2011:475:27-30

16 Thomas P, Bracken P, Timimi P. The limits of evidence-based medicine in psychiatry. Philos Psychiatr Psychol 2012;19:295-308.

17 Angell M. The illusions of psychiatry. The New York Review of Books [Internet]. 14 July 2011 [cited 31 December 2012]. http://www.nybooks.com/articles/archives/ 2011/jul/14/illusions-of-psychiatry/?pagination=false

18 Kendall T. The rise and fall of the atypical antipsychotics. Br J Psych 2011;199:266-8.

19 Thomas P. Towards a critical perspective on 'narrative loss' in schizophrenia. In Morgan A.ed. Being human: reflections on mental distress in society. Ross-on-Wye, England: PCCS Books, 2008:24-39.

20 Laing RD. The divided self: an existential study in sanity and madness. London: Tavistock Publications, 1960.

21 Read J, Perry BD, Moskowitz A, et al. The contribution of early traumatic events to schizophrenia in some patients: a traumagenic neurodevelopmental model. Psychiatry 2001;64:319-45.

22 Janssen I, Hanssen M, Bak R, et al. Discrimination and delusional ideation. Br J Psych 2003;182:71-6.

23 Zubin J, Spring B. Vulnerability: a new view of schizophrenia. J Abnormal Psych 1977;86:103-26.

24 Herman JL. Trauma and recovery. New York: Basic Books, 1992

25 Longden E, Madill A, Waterman MG. Dissociation, trauma, and the role of lived experience: toward a new conceptualization of voice hearing. Psych Bull 2012;138:28-76. 
26 Moskowitz A, Read J, Farrelly $\mathrm{S}$, et al. Are psychotic symptoms traumatic in origin and dissociative in kind? In: Dell PF, O'Neill JA, skowitz A, Schäfer I, Dorahy MJ. eds. Psychosis, trauma and dissociation: emerging perspectives on severe psychopathology. Oxford, England: Wiley-Blackwell, 2008:281-95.

27 Ross CA.. Dissociative schizophrenia. In: Moskowitz A. Psychosis, trauma and dissociation: emerging perspectives on severe psychopathology. Oxford, England: Wiley-Blackwell, 2008:281-95.

28 Rudegeair T, Farrelly S. Is all psychosis dissociative? Paper presented at the Annual Conference of the International Society for the Study of Dissociation; November 2003, Chicago, IL.

29 Varese F, Smeets F, Drukker M, et al. Childhood adversities increase the risk of psychosis: a meta-analysis of patient-control, prospective and cross-sectional cohort studies. Schiz Bull 2012;38:661-71.

30 Kuhn T. The structure of scientific revolutions. 2nd edn. Chicago, IL: University of Chicago Press, 1962.

31 Kleinman A. The art of medicine. Catastrophe and caregiving: the failure of medicine as an art. Lancet 2008;371:22-3.

32 Sevenhuijsen S. Citizenship and the ethics of care: feminist considerations on justice morality and politics. London: Routledge, 1998.

33 Sevenhuijsen $S$. The place of care: the relevance of the feminist ethic of care for social policy. Feminist Theory 2003;4:179-97.

34 Gilligan C. In a different voice: psychological theory and women's development. Cambridge, MA: Harvard University Press, 1982.

35 Noddings N. Caring: a feminine approach to ethics and moral education. Berkeley, CA: University of California Press, 1986.

36 Merleau-Ponty M. Phenomenology of perception (Smith C, trans). London: Routledge \& Kegan Paul, 1962. (see especially Chapter 3, pp. 98-147).

37 Matthews E. The philosophy of Merleau-Ponty. Chesham, England: Acumen, 2002.

38 Gergen K. Realities and relationships: soundings in social construction. Cambridge, MA: Harvard University, Press, 1997.

39 Bloom S. Creating sanctuary: towards the evolution of safe communities. London: Routledge, 1997.

40 Kleinman A, van der Geest S. 'Care' in health care and medicine: remaking the moral world of medicine. Medische Anthropol 2009;21:159-68.

41 Heidegger M. Being and time (Macquarrie J, Robinson E, trans). Oxford, England: Blackwell, 1964.

42 Thomas P. Soteria: contexts, practice and philosophy. In: Coles S, Keenan S, Diamond B, Madness contested: power and practice. Ross-on-Wye, England: PCCS Books, 2013:141-57.

43 Buber MI. Thou. Edinburgh, England: T. \& T. Clarke, 1937/1970.

44 Noddings N. Starting at home: caring and social policy. Berkeley, CA: University of California Press, 2002.

45 Stastny P, Lehmann P, eds. Alternatives beyond psychiatry. Berlin: Peter Lehmann Publishing, 2007

46 Bakhtin M. The dialogic imagination (Holquist M, ed and Emerson C, Holquist M., trans). Austin, TX: University of Texas Press, 1981.
47 Good P. Language for those who have nothing: Mikhail Bakhtin and the Landscape of Psychiatry. New York, NY: Kluwer Academic Publishers/Plenum, 2001.

48 Charon R, Banks J, Connelly J, et al. Literature and medicine: contributions to clinical practice. Ann Intern Med 1995;122:599-606.

49 Charon R. Narrative medicine: honoring the stories of illness. New York, NY: Oxford University Press, 2008.

50 Johnson M. Moral imagination. Chicago, IL: University of Chicago Press, 1993.

51 Lederach JP. The moral imagination: the art and soul of building peace. New York, NY: Oxford University Press, 2005.

52 Program in Narrative Medicine [Internet]. New York: Columbia University Medical Center [cited 22 December 2012]. http://www.narrativemedicine.org/about/people. html

53 Brison S. Aftermath: violence and the remaking of the self. Princeton, NJ: Princeton University Press, 2002.

54 Dillon J. The personal is the political. In: Rapley M, Moncrieff J, Dillon J, eds. De-medicalizing misery: psychiatry, psychology and the human condition. Eastbourne, England: Palgrave Macmillan, 2011:141-57.

55 Mollica R. The trauma story: the psychiatric care of refugee survivors of violence and torture. In: Ochberg F, ed. Post-traumatic therapy and victims of violence. New York, NY: Brunner/Mazel, 1988:295-314.

56 Kofman S. Smothered words (Dobie M, trans). Evanston, ILL: Northwestern University Press, 1998.

57 Stone B. Towards a writing without power: notes on the narration of madness. Auto/Biography 2004;12:16-33.

58 Frank A. The wounded storyteller: body, illness and ethics. Chicago, IL: University of Chicago Press, 1995

59 Wilson J, Droždek B. Broken spirits: the treatment of traumatized asylum seekers, refugees, and war and torture victims. New York, NY: Brunner-Routledge, 2004.

60 Agger I, Jensen SB. Testimony as ritual and evidence in psychotherapy for political refugees. J Trauma Stress 1990;3:115-30.

61 Bloom S, Farragher B. Destroying sanctuary: the crisis in human service delivery systems. New York, NY: Oxford University Press, 2010.

62 Mosher L. Soteria and other alternatives to acute psychiatric hospitalization: a personal and professional review. J Nerv Ment Dis 1999; 187:142-9

63 Mosher LR, Hendrix V, Fort DC. Soteria: through madness to deliverance. Bloomington, IN: XLibris, 2004.

64 Calton T, Ferriter M, Husband N, et al. A systematic review of the Soteria paradigm for the treatment of people diagnosed with schizophrenia. Schiz Bull 2008;34:181-92.

65 Lewis B. Narrative psychiatry: how stories can shape clinical practice. Baltimore, MD: The Johns Hopkins University Press, 2011.

$66 \mathrm{Mol}$ A. The body multiple: ontology in medical practice. Durham, NC: Duke University Press, 2002.

67 Hammersley P, Read J, Woodall S, et al. Childhood trauma and psychosis: the genie is out of the bottle. J Psych Trauma 2007;6:7-20. 